ARoueología Y SocIEDAD

№ 26, 2013: 91-110

ISSN: 0254-8062

RECIBIDO: 5 / NOV. / 2012

ACEPTADO: 20 / ABR. / 2013

\title{
ANÁLISIS DE ARCILLASY MATERIAL COMPARATIVO POR MEDIO DE DIFRACCIÓN DE RAYOS XY PETROGRAFÍA PARA KUNTUR WASI, CAJAMARCA, PERÚ
}

\author{
ISABELLE DRUC \\ UniVERSIDAD DE WISCONSIN-MADISON, DEPARTAMENTO DE ANTROPOLOGÍA \\ icdruc@wisc.edu \\ KINYA INOKUCHI \\ UnIVERSIDAD DE SAITAMA, FACULTAD DE ARTES LIBERALES \\ inokuchi@mail.saitama-u.ac.jp \\ ZHIZHANG SHEN \\ Universidad de Wisconsin-Madison, DePARTAMENTO dE GEOCIENCIAS \\ zshen5@wisc.edu
}

\section{RESUMEN}

Varias arcillas, temperantes y suelos recolectados alrededor del sitio formativo ceremonial de Kuntur Wasi, en los Andes norcentrales de Perú, fueron analizados con difracción de Rayos X y petrografía para determinar su composición y disponibilidad para la producción cerámica antigua. Los resultados muestran que la arcilla analizada de Sangal es una ilita, que las muestras de San Pablo tienen poco material arcilloso y que el temperante volcánico usado por los alfareros de Mangallpa es similar al temperante en muchas cerámicas de Kuntur Wasi. Se postula que parte de la producción antigua se hacía con material de la zona de Mangallpa, llevado a Kuntur Wasi para una elaboración in-situ, o que las cerámicas se traían ya hechas. Análisis de arcillas del valle medio del Jequetepeque revela la presencia de caolín, lo cual es ausente en las muestras analizadas de la región de Kuntur Wasi.

PalabRas Clave: Producción cerámica, difracción de Rayos X, petrografía, arqueología andina, etnoarqueología.

\section{Abstract}

X-ray diffraction and petrographic analyses of soils, clays and tempers collected around the archaeological site of Kuntur Wasi, near San Pablo, in the northern Peruvian Andes, aim at investigating the composition of local materials and the possibility of on-site production. The results of the XRD study shows that the 
analyzed clay found around the site is an illite, while the other collected soils from San Pablo are not clays of ceramic production range. The volcanic temper used by modern potters eight kilometers north of the archaeological site is very similar to the temper observed in many of the ancient ceramics from Kuntur Wasi. Also, analysis of clays from the middle Jequetepeque valley shows the presence of kaolin, which is absent from the analyzed clays in the Kuntur Wasi region.

KEYwords: Ceramic production, X-ray diffraction, petrography, Andean archaeology, ethnoarqueology.

\section{INTRODUCCIÓN}

Un programa de análisis de pastas de cerámica provenientes del sitio arqueológico de Kuntur Wasi en la provincia de San Pablo, departamento de Cajamarca, fue iniciado por Isabelle Druc y Kinya Inokuchi, investigador del Proyecto Arqueológico Kuntur Wasi. El objetivo de este programa era estudiar la procedencia de la cerámica encontrada en Kuntur Wasi y sus modalidades de producción. Kuntur Wasi es un centro ceremonial del Formativo del primer milenio a.C. en los Andes nor-centrales, ubicado a $2300 \mathrm{msnm}$. Se encuentra en la parte alta del valle del Jequetepeque, más o menos a unos 35 kilómetros de la ciudad de Cajamarca (Figs. 1 y 2).

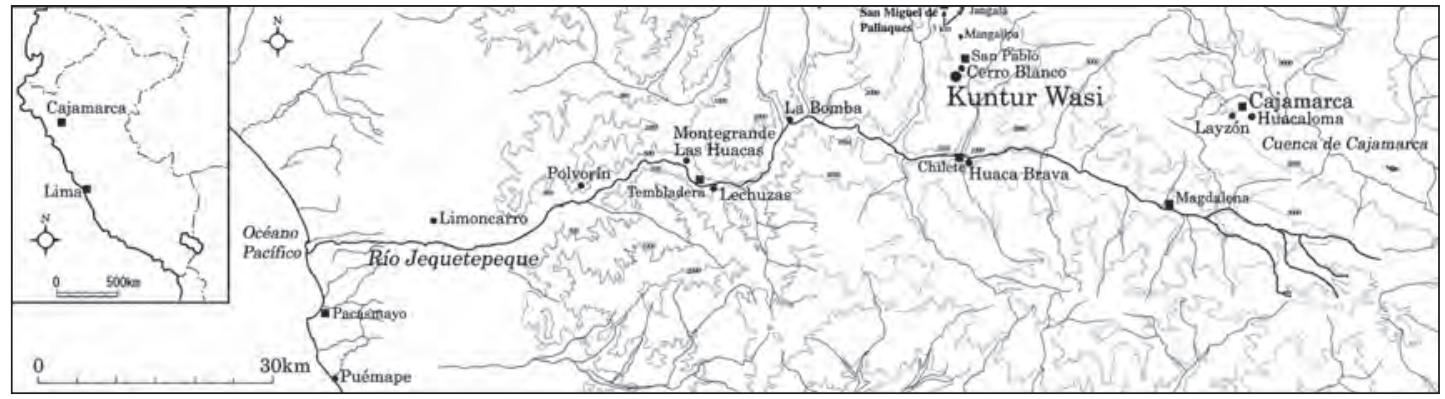

Figura 1. Valle del Jequetepeque, con ubicación de Kuntur Wasi y de los principales sitios mencionados en el texto. Adaptado de Inokuchi (2010: Fig. 1).

Las excavaciones en Kuntur Wasi fueron realizadas por un proyecto arqueológico japonés entre 1988 y 2002. El sitio adquirió mucha fama cuando se encontraron ocho tumbas intactas, con muchos objetos de oro, coronas, collares, aretes y exquisitas vasijas de cerámica (Onuki et al. 1995; Onuki e Inokuchi 2011). Además, los cuatro niveles de ocupación identificados, los cuales abarcaron más o menos 900 años, produjeron una gran cantidad de fragmentos de cerámica.

El programa de análisis de pastas se inscribe dentro de una problemática de desarrollo del centro ceremonial y de cambios que se observan en la arquitectura, en las fases de construcción y en varios estilos cerámicos. Se sugiere un origen foráneo de uno (o más) grupo(s) humano(s) responsable(s) de muchos de los cambios observados (Onuki et al. 1995; Inokuchi 2010). Por consecuencia, parte de los análisis de cerámica se orientan a determinar lo local de lo intrusivo, identificar diferencias de tradiciones tecnológicas y ver si los estilos foráneos son imitaciones o importaciones.

Para cumplir con estos objetivos, se necesitó obtener datos de referencia sobre la geología local, las posibilidades de producción al nivel local, la disponibilidad de arcillas y temperantes y las actuales prácticas de los alfareros tradicionales en la región. Se recolectaron muestras comparativas (arcillas, temperantes, cerámicas modernas, sedimentos y rocas ${ }^{1}$ ) para análisis con difracción de rayos X (DRX)

1 Los resultados del estudio de la mayoría de las rocas y arenas recolectadas se publicará en otro articulo, en colaboración con Pedro Navarro y Victor Carlotto del INGEMMET, en Lima. 
y petrografía, y se llevó a cabo un estudio etnográfico detallado sobre la tradición alfarera de la región (Druc 2011). También se analizaron algunas arcillas por espectrografía. Estos estudios forman la base comparativa para interpretar los datos cerámicos arqueológicos y son los que presentamos aquí. Una línea de investigación adicional se inició para comprobar la presencia de manganeso en las cerámicas de Kuntur Wasi con el fin de explicar el color totalmente negro de muchas pastas. Este análisis originó de una conversación con el Sr. Lorenzo Cabrera, ceramista de Cajamarca experto en reproducción de material arqueológico andino, que utiliza manganeso para

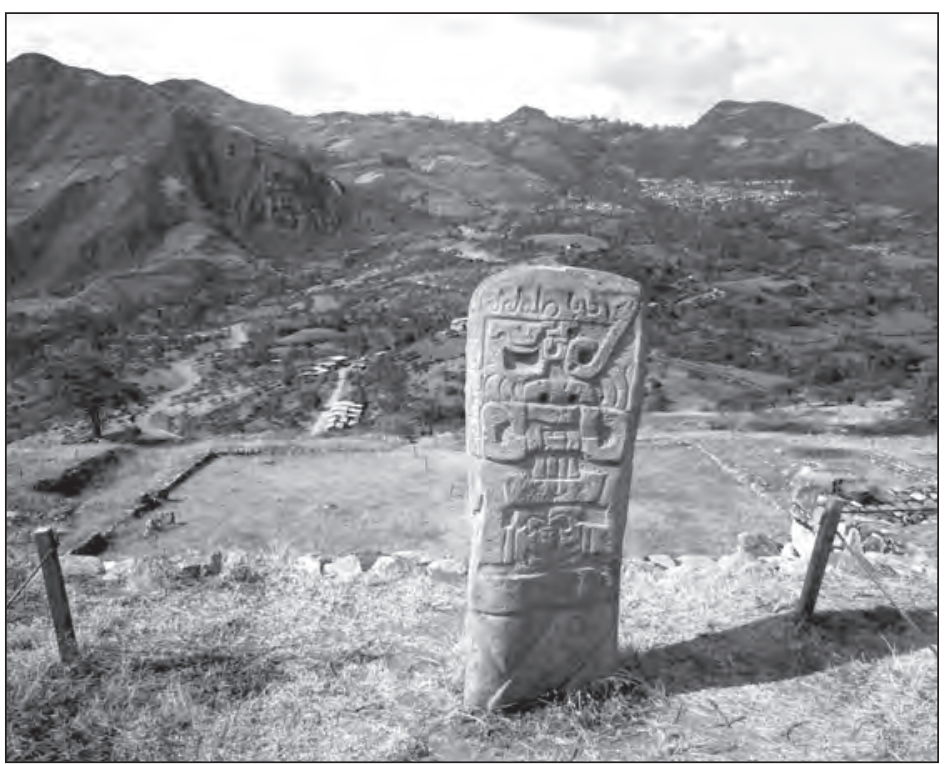

Figura 2. Centro ceremonial de Kuntur Wasi, mirando hacia el noreste. En el fondo se ve el pueblo de San Pablo. Foto I. Druc 2010. reproducir ciertas cerámicas. Este material se encuentra fácilmente en la región y es un aditivo conocido para dar un color negro al cuerpo o a la superficie de las vasijas (Clark 2001; Rhodes 1973).

A continuación, presentamos primero los datos arqueológicos, etnográficos y geológicos conocidos para Kuntur Wasi, seguido de un resumen de los estudios de cerámica al nivel regional, para luego presentar la metodología, los resultados de análisis de las muestras comparativas y arqueológicas y una discusión incorporando los diversos datos disponibles.

\section{ANTECEDENTES DE INVESTigación}

\section{DATOS ARQUEOLÓGICOS}

El centro ceremonial de Kuntur Wasi fue ocupado durante el primer milenio a.C. Se notan cuatro fases arqueológicas mayores (Inokuchi 2010). El estudio de las fases de construcción, las tumbas, cerámica y otros materiales culturales, sugieren que hubo un periodo inicial restringido y local (fase Ídolo), seguido por una transformación importante del centro ceremonial y el posible ingreso de un grupo humano no local (fase Kuntur Wasi). El sitio crece significativamente con nuevas construcciones durante la fase Copa y empieza a declinar en la fase Sotera con cambios drásticos y un cuasi abandono de la función ceremonial del sitio. Aparte de las cuatro fases principales de construcción y material asociado, se identificó una sub-fase estilística durante la fase Kuntur Wasi, con cerámica al parecer local llamada «complejo Sangal» (Inokuchi 2010; Onuki et al. 1995).

El análisis estilístico de la cerámica sugiere la existencia de una cerámica local y de estilos alógenos o con influencias de la costa norte del Perú y de la sierra norte, con una tipología identificando 61 grupos estilísticos distintos (Inokuchi 2010). Aunque Kuntur Wasi este dentro del horizonte estilístico y cultural Chavín, del Horizonte Temprano, el sitio no parece haber recibido un impacto directo del centro ceremonial de Chavín de Huantar (Inokuchi 1998).

Con el objetivo de identificar y diferenciar lo local de lo foráneo, y los posibles lugares de origen. se colectaron muestras de cada grupo estilístico de cada fase arqueológica, cada fragmento siendo 
de procedencia arqueológica con posición espacial y estratigráfica conocida. Los grupos estilísticos difieren según su acabado (e.g. con o sin engobe, bruñido, pulido, rojo sobre blanco), textura (e.g. cerámica fina, pulida, tosca), o decoraciones (e.g. inciso, líneas bruñida). Dentro de estas categorías hay vasijas con diferentes formas (e.g. cuencos, botellas, ollas, copas). Un total de 88 muestras fueron preparadas para análisis petrográfico, que permitió identificar cuatro petrogrupos mayores distinguidos por la presencia de material volcánico (Petrogrupos A y C), intrusivo intermedio (Petrogrupo B) y volcánico-sedimentario (Petrogrupo D). En cada grupo, variaciones internas de composición mineral apuntan a la explotación de varias fuentes distintas y probablemente numerosos talleres o lugares de producción. Cabe notar que el material intrusivo, característico del Petrogrupo B, no tiene equivalente en la geología del sitio. Este grupo representa 30,68\% de las cerámicas de Kuntur Wasi analizadas contra 48,88\% para el Petrogrupo A. Este último es considerado de origen local o de la región inmediata debido al carácter volcánico de la geología alrededor del sitio arqueológico. La correlación con formas y datos estilísticos muestra que no existe una receta especial de pasta para la producción de una forma o de un estilo particular de vasijas. Sin embargo, se nota la tendencia de afinar la pasta para cerámicas finas y botellas (granulometría fina de las inclusiones minerales) y de trabajar con una pasta más gruesa para ollas o cuencos grandes.

\section{DATOS ETNOGRÁFICOS}

No se encontró ningún taller cerámico en o cerca de Kuntur Wasi. Tampoco se extrae arcilla cerca del sitio ceremonial ahora. El centro actual de producción cerámica más próximo, Mangallpa (Cuscuden), se localiza a unos $7 \mathrm{~km}$ al norte del sitio arqueológico, lo que representa un viaje de tres horas a pie. Tal distancia la recorren los alfareros de Mangallpa para vender sus ollas en el mercado dominical de San Pablo cerca de Kuntur Wasi. La otra área de producción se encuentra aún más al norte, en Jangalá, un pequeño pueblo de la provincia de San Miguel de Pallaques, a $16 \mathrm{~km}$ al norte de San Pablo en línea directa. Las fuentes de arcilla y temperante se encuentran entre Mangallpa y Jangalá, en el área de Jancos Alto y Cerro Cuscuden. El temperante es una arena volcánica con inclusiones de cuarzo, plagioclasa, toba volcánica y fragmentos piroclásticos. La arcilla se encuentra a menos de $2 \mathrm{~km}$ de Mangallpa y la arena un poco más lejos, entre media hora y una hora a pie según las fuentes. Cabe notar que una muestra de sedimento arenoso colectada en 2012 en Jancos Alto, $2 \mathrm{~km}$ al norte de Mangallpa, contiene fragmentos subvolcánicos erosionados. Las ollas producidas son ollas para cocinar, jarras y tiestos (en Jangalá) para consumo doméstico (para más detalles véase Druc 2011).

Un punto importante es la costumbre de los alfareros de Mangallpa de salir a producir dos o tres meses al año. Esta itinerancia les lleva a pueblos lejanos, en la sierra y hasta la costa, a distancias de 30 a $50 \mathrm{~km}$ de su pueblo de origen

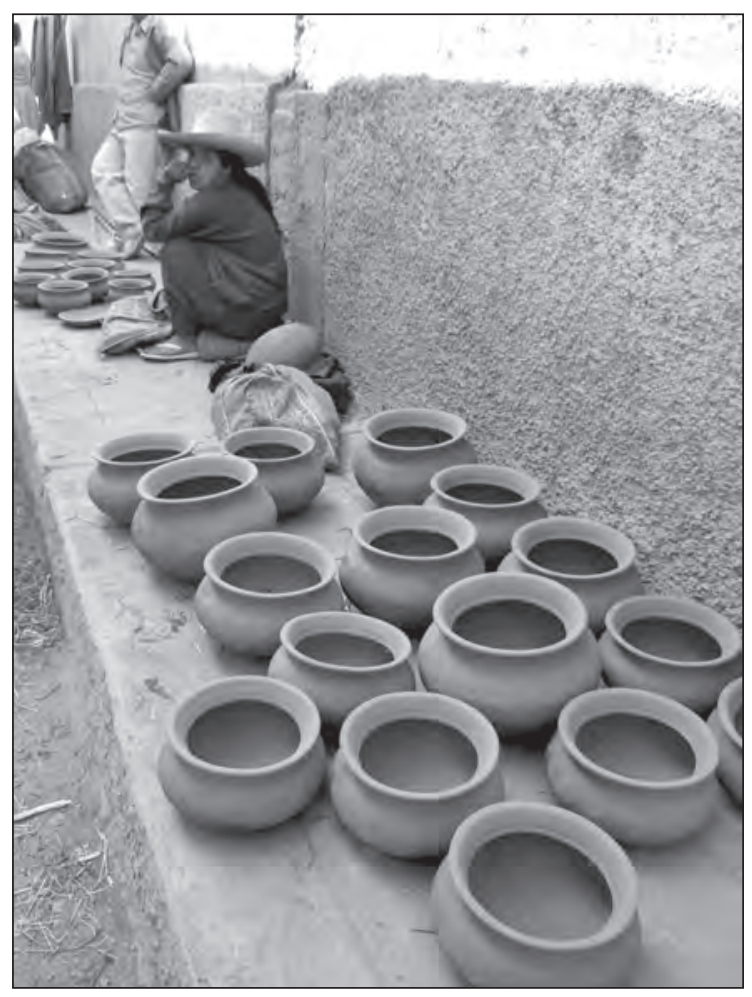


(Druc 2011; Ramón 2008, 2011). Los artesanos salen con sus materiales listos. Esta costumbre es reducida ahora, tanto en el número de alfareros viajantes como en la extensión de sus viajes. Antiguamente era muy común y los alfareros de Mangallpa son conocidos en todo el departamento de Cajamarca. La cantidad de ollas producidas en Mangallpa (unas 20 mil por semana) y la relativa proximidad de este pueblo al sitio arqueológico designa a esta región como fuente de las materias primas para la producción cerámica antigua, y/o lugar de producción de parte de la cerámica encontrada en Kuntur Wasi.

\section{DATOS GEOLÓGICOS ${ }^{2}$}

La geología local alrededor de Kuntur Wasi se caracteriza por depósitos volcánicos del Terciario (del final del Paleoceno al Mioceno) caracterizado por ignimbritas soldadas, rocas riolíticas con abundantes fenocristales de cuarzo, plagioclasa y biotita, pómez y fragmentos líticos polimícticos (Navarro et al. 2008). Estos depósitos yacen sobre rocas sedimentarias del Jurásico Superior al Cretáceo Superior (ibíd.; Navarro y Flores 2007). También se encuentra una pequeña zona metamórfica y depósitos aluviales del Cuaternario en San Pablo. Las rocas volcánicas locales son tufos riolíticos, dacitas y andesitas, con intercalación de areniscas, conglomerados, tobas y piroclásticos (Reyes Rivera 1980: 38, 39, 41). Un acantilado de rocas riolíticas se encuentra justo al sur del sitio arqueológico (Yomoda 2002). Los materiales sedimentarios incluyen cuarcitas, areniscas, lutitas, calizas, margas, y limoarcillitas. Se nota también en el área una fuerte alteración termal de las rocas y grandes derrumbes (Shimizu, comunicación personal, febrero 2013).

Al nivel regional, y de importancia para nuestro tema, se nota la presencia de tres cuerpos intrusivos a $20 \mathrm{~km}$ y más del sitio arqueológico. Estos cuerpos se encuentran: 1. En la región de San Miguel de Pallaques a $20 \mathrm{~km}$ al norte de Kuntur Wasi; 2. Al sur del río Jequetepeque y Chilete, cerca de Contumaza/Cerro Tanta Rica (más de 22 km de Kuntur Wasi); y 3. A 25 km al suroeste de San Pablo, en la región de Tembladera (Navarro y Flores 2007; Navarro 2008, 2011; Victor Carlotto y Pedro Navarro comunicación personal, agosto 2011). Estos cuerpos son de composición intermedia: granodiorita, diorita y tonalita, cortando los niveles volcánicos y sedimentarios (Navarro 2012; Reyes Rivera 1980: 45). En 2011 se recolectaron muestras líticas procedentes de estos cuerpos en una tentativa de identificar el origen del material intrusivo presente en las cerámicas de Kuntur Wasi (Druc et al. 2013). Sin embargo, el análisis de muestras comparativas recolectadas en 2012 sugiere que los alfareros antiguos utilizaron más bién arenas con material intrusivo derivado de las rocas madres. También en 2012 se descubrió una fuente de material detrítico erosionado con fragmentos subvolcánicos en Jancos Alto cerca de Mangallpa. Esta fuente es clasificada como depósito eluvial (Pedro Navarro, comunicación personal, noviembre 2012). Es la única muestra de Mangallpa con está composición.

\section{ESTUDIOS CERÁMICOS AL NIVEL REGIONAL}

Al nivel regional nor-andino, algunos estudios de pasta ofrecen datos comparativos importantes para Kuntur Wasi. Se trata de los análisis de la cerámica de Montegrande, en el valle medio del Jequetepeque, y de Huacaloma y Layzon en la cuenca de Cajamarca (Seki et al. 2009; Tellenbach 1986; Terada y Onuki 1988; Wagner et al. 1994). Kuntur Wasi se encuentra a la mitad del camino entre estas dos regiones, a menos de $40 \mathrm{~km}$ de cada sitio. Cornelius Ulbert (1994) hizo un análisis muy detallado de la cerámica de Montegrande, combinando estudios petrográficos (Riederer ms), tecnológicos, estilísticos y arqueológicos. Ulbert determinó que la cerámica se manufacturó con la técnica del enrollado y que tiene paralelos estilísticos con cerámicas de Cerro Blanco (sitio ceremonial al lado de Kuntur Wasi pero un

2 Para una presentación más detallada de la geología local y regional véase Druc et al. 2013; Navarro et al. 2008; Noble y Loayza 2004. 
poco más temprano que éste ${ }^{3}$ y Huacaloma temprano (Ulbert 1994). Propone la existencia de un alfar de producción local caracterizado por un temperante de nódulos de arcilla durante la primera fase de ocupación del sitio, seguido por la adopción adicional de un alfar de cerámica utilitaria de producción halógena con temperante de plagioclasas en la segunda fase de ocupación. Este alfar, por las formas y el temperante, se asimila a la producción observada en el sitio de Huacaloma, Cajamarca (Ulbert 1994). Los estudios de espectroscopia Mössbauer y activación neutrónica hechos por Wagner et al. (1994) de cerámicas de Montegrande y de una muestra de arcilla local confirman las observaciones petrográficas. En Cajamarca, el análisis de cerámicas de los sitios formativos Huacaloma y Layzon revela la presencia de muchas inclusiones de plagioclasa (tipo albita) y menor cantidad de biotita, hornblenda, cuarzo y fragmentos de roca, aunque no se precisa de cuál tipo de roca se trata (Seki et al. 2009). En fases posteriores (Cultura Cajamarca) esta tendencia es reemplazada por la presencia de mucho cuarzo en la pasta (ibíd.). Asimismo, estudios por difracción de Rayos X sugieren que la temperatura de cocción de las cerámicas analizadas pasaba los $500^{\circ} \mathrm{C}$. y los alfareros utilizaron caolín, montmorillonita y tufo de andesita alterado hidrotermalmente (Seki et al. 2009: 3).

Ahora presentaremos las muestras y los métodos de análisis. Luego daremos los resultados de los análisis, seguidos por una discusión.

\section{Metodos}

Para la caracterización de los minerales arcillosos con DRX se analizaron ocho muestras de materia prima (Cuadro 1) más una muestra experimental de quema de la arcilla SG30. Las muestras fueron colectadas en o cerca de la casa de los alfareros entrevistados o con personas locales que conocían las fuentes de arcillas alrededor del sitio arqueológico. La muestra de arcilla de Sangal (SG30) resultó de particular interés, siendo la arcilla conocida más cercana a Kuntur Wasi. Viene del lecho de un arroyo en Sangal, a un kilómetro al sur de Kuntur Wasi. El material tiene un aspecto blanquizo con venas morenas anaranjadas, y es muy plástico. Sin embargo, no es utilizado para la producción cerámica actual. Los alfareros en Mangallpa buscan sus materiales en otro sitio ubicado más cerca de su lugar de producción. La presencia de manganeso fue investigada en seis muestras arqueológicas con pastas negras (ID6, ID10, KW24, KW26, CP64 y CP54), proviniendo de las fases arqueológicas Ídolos, Kuntur Wasi y La Copa.

Cuadro 1: Identificación de las muestras comparativas analizadas (distancias geodésicas)

\begin{tabular}{|llll|}
\hline Muestras & ORIgEN (KW=Kuntur Wasi) & ANÁLISIS & InFormación \\
\hline SG30 & Sangal, arroyo, 1 km al sur de KW. & $\begin{array}{l}\text { DRX } \\
\text { petro }\end{array}$ & Arcilla blanca. \\
MA22 & Mangallpa, pueblo, 7 km al norte de KW. & $\begin{array}{l}\text { DRX } \\
\text { petro }\end{array}$ & Arcilla morena. \\
MA25 & Mangallpa, pueblo, 7 km de KW. & DRX & Arcilla morena. \\
MA23 y MA26 & $\begin{array}{l}\text { Mangallpa, cerro Cuscuden, 9 km al norte } \\
\text { de KW. }\end{array}$ & petro & Temperantes. \\
MA24 y MA27 & Mangallpa, pueblo, 7 km al norte de KW. & petro & Cerámica tradicional. \\
SP29 & San Pablo, 2 km al norte de KW. & DRX & Arcilla morena. \\
\hline
\end{tabular}

3 Las excavaciones en Kuntur Wasi solo empezaron en 1988 y el material cerámico no había sido estudiado cuando Cornelius Ulbert hizo el análisis de la cerámica de Montegrande, lo que impidió estudios comparativos entre los dos sitios. 
I. Druc, K. Inokuchi y Z. Shen / Análisis de arcillas y material comparativo por medio de difracción...

\begin{tabular}{|c|c|c|c|}
\hline LA28 & La Laguna, $3 \mathrm{~km}$ al norte de KW. & DRX & Suelo arcilloso negro. \\
\hline JA1 & Jangalá Pueblo, 16 km al norte de KW. & $\begin{array}{l}\text { DRX } \\
\text { Petro }\end{array}$ & Arcilla morena. \\
\hline JA2 & Jangalá Pueblo, 16 km al norte de KW. & $\begin{array}{l}\text { DRX } \\
\text { petro }\end{array}$ & Temperante arenoso. \\
\hline JA4 y JA5 & Jangalá Pueblo, 16 km al norte de KW. & petro & Cerámica tradicional. \\
\hline Li1 & Sangal, $500 \mathrm{~m} \mathrm{KW}$, corte de carretera. & petro & Deposito sedimentario. \\
\hline $\mathrm{Mn}$ & Cajamarca, L. Cabrera, mina local. & DRX & Aditivo. \\
\hline MTJ3 & $\begin{array}{l}\text { Pampa de las Hamacas } \\
17 \text { M } 7046379202461-572 \mathrm{~m} .\end{array}$ & $\mathrm{TSP}$ & Arcilla. \\
\hline MTJ4 & $\begin{array}{l}\text { Corte de carretera antes de llegar a Las } \\
\text { Huacas } 17 \text { M } 7029369201354-432 \mathrm{~m} .\end{array}$ & TSP & Arcilla. \\
\hline MTJ5 & $\begin{array}{l}\text { Lecho de la represa Gallito Ciego, debajo } \\
\text { del restaurante Campestre de Juan Dávalos } \\
\text { Cerdán } 17 \text { M } 7038329200717 \text { - } 415 \text { m. }\end{array}$ & TSP & Tierra colorada arcillosa. \\
\hline MTJ10 & $\begin{array}{l}\text { Canal de riego, La Bomba } \\
17 \text { M } 7168429205316-589 \mathrm{~m}\end{array}$ & TSP, petro & Tierra mitosa. \\
\hline MM14a & $\begin{array}{l}\text { Pasta preparada (mito,arena) Sr. Alvito, } \\
\text { Cuscuden Mangallpa. }\end{array}$ & TSP, petro & Pasta cruda. \\
\hline MM14b & Sr. Alvito, Mangallpa. & DRX, petro & Arcilla \\
\hline MM15 & Jancos Alto. & petro & $\begin{array}{l}\text { Arena, mina para temper- } \\
\text { ante. }\end{array}$ \\
\hline MKW18 & Quebrada Sangal. & petro & Arena. \\
\hline
\end{tabular}

\section{DIFRACCIÓN DE RAYOS X (DRX)}

La DRX complementa el análisis petrográfico el que, por cuestión de resolución visual, no permite el análisis de inclusiones de la talla de las arcillas. La DRX permite medir las distancias interplanas $d$ de la red cristalina de los minerales, características de cada mineral. Se utiliza la ley de Bragg ( $n \lambda=2 \mathrm{~d}$ $\operatorname{sen} \theta$ ), analizando el ángulo de difracción entre los rayos X incidentes monocromáticos y los rayos resultantes cuando la ley de Bragg se cumple. Se relaciona la longitud de onda de la radiación electromagnética con los planes cristalinos (Brindley y Brown 1980; Moore y Reynolds 1997). Los análisis DRX fueron hechos con la ayuda de Zhizhang shen, en el laboratorio de DRX del Dr. Huifang Xu, en el departamento de Geociencias y Ciencias Materiales de la Universidad de Wisconsin-Madison. Se utilizaron difractómetros Scintag Pad V y Rigaku Rapid II. El Rigaku Rapid II permitió un análisis más rápido sin necesidad de reducir la muestra a polvo. El Scintag Pad V opera a $45 \mathrm{kV}, 40 \mathrm{~mA}$ con radiación Cu $\mathrm{K} \alpha$. Se realizó un análisis global para un estudio de los componentes mayoritarios en la muestra total, y un análisis de la arcilla en suspensión. El análisis global analizó los minerales sin orientación de los agregados y solo necesitó una pulverización de la muestra en un mortero de ágata. Las muestras de arcillas SP29 y LA28 estaban húmedas cuando fueron recolectadas. Fueron secadas en una cápsula de Petri en el horno del laboratorio por seis horas a $60^{\circ} \mathrm{C}$ antes de ser reducidas a polvo.

El análisis de la arcilla en suspensión exigió una preparación con etilénglicol que permite la separación de la fracción fina arcillosa de los minerales arcillosos más gruesos. Así, los minerales arcillosos son en suspensión y libres de orientarse según su orientación preferencial. Con un cuentagotas se puso la suspensión en el centro de una lámina de vidrio y se secó en el horno durante dos horas a $60{ }^{\circ} \mathrm{C}$. El tratamiento con etilénglicol siguió las pautas directivas de la United States Geological Society. 
Para averiguar la presencia de manganeso en las cerámicas arqueológicas, se utilizó el Rigaku Rapid II con radiación Mo K $\alpha$ a $50 \mathrm{kV}$, y $50 \mathrm{~mA}$. Cada muestra (diámetro = 1 2 mm) fue pegada sobre el tubo de vidrio y analizada tal cual.

\section{ESPECTROSCOPÍA MINERAL PARA ANÁLISIS DE ARCILLAS}

Elizabeth Ordoñez Lopez, del INGEMMET en Lima, realizó el análisis de cuatro muestras de material arcilloso del valle medio del Jequetepeque (MTJ3, 4, 5, 10), y una muestra de Mangallpa (MM14 Cuadro 1). La espectrocopía permite un análisis no destructivo y rápido con identificación de los minerales principales en una muestra. Los espectros de análisis fueron obtenidos mediante TerraSpec, con determinación espectrográfica hecha al comparar las longitudes de onda de las muestras con las longitudes existentes en la base de datos del equipo (calibración interna).

\section{PETROGRAFÍA}

La petrografía permite la identificación de los minerales no plásticos y fragmentos de roca presente en la pasta cerámica, observaciones sobre textura, distribución y talla de las inclusiones e inferencias sobre procedencia y tecnología cerámica. Triangulando los datos petrográficos con los datos arqueológicos, estilísticos, y geológicos, se ofrece una base más sólida para los estudios socioeconómicos, culturales y políticos en relación con las sociedades antiguas (Rice 1987; Stoltman 1991; Velde y Druc 1999).

\section{RESUltAdOS DE LOS ANÁLISIS CON DIFRACCIÓN DE RAYOS X}

\section{a) IDENTIFICACIÓN DE LOS MINERALES ARCILLOSOS}

El cuadro 2 presenta las fases minerales identificadas por DRX. Los resultados son comentados abajo.

Cuadro 2: Fases minerales identificadas por DRX

\begin{tabular}{|lll|}
\hline MuESTRAS & FASES MAYORES IDENTIFICADAS & FASES MENORES \\
\hline SG30 & Cuarzo, esmectita, ilita, anatasa TiO2). & Clorita/caolinita. \\
SG30 con orientación de & Ilita $(>90 \%)$. & Esmectita $(<10 \%)$. \\
los agregados & Cuarzo, ilita, albita y esmectita. & Clorita/caolinita. \\
MA22 & Cuarzo, ilita, albita y esmectita. & Clorita/caolinita. \\
MA25 & Esmectita. & \\
MM14b & Cuarzo, ilita. & Caolinita, anatasa, albita. \\
SP29 & $\begin{array}{l}\text { Cuarzo, albita, phillipsita (tectosilicato } \\
\text { hidratado, zeolita). }\end{array}$ & Ilita y esmectita. \\
LA28 & Plagioclasa y cuarzo. & \\
JA1 & Plagioclasa y cuarzo. & Clorita, ilita, esmectita. \\
JA2 & &
\end{tabular}

\section{Observaciones}

Arcilla SG30 de Sangal

En el difractograma para el análisis global (Fig. 4), el pico de clorita/caolinita no permite una distinción clara. Aunque los picos de clorita puedan superponerse a los del caolín, es probable que la clorita esté presente en el mineral principal. Los picos anchos entre $d=13 \AA$ y $d=10 \AA$ pueden resultar de ni- 
veles mixtos de ilita/esmectita (Grathoff y Moore 1996). Para aclarar este punto, se analizó la fracción arcillosa en suspensión.

El tratamiento con etilénglicol (EG - línea mediana Fig. 5) para obtener una orientación de los minerales, confirmó la presencia de niveles mixtos de esmectita e ilita. Para identificarlos mejor, se puso la lámina con los agregados orientados por un lapso de una hora a $400^{\circ} \mathrm{C}$ y después se reanalizó. La idea se basa en que la red cristalina de la esmectita se destruye llegando a los $400^{\circ} \mathrm{C}$, pero no cambia para la ilita. Con este tratamiento, los picos de esmectita desaparecieron y solo el pico (001) de ilita pemaneció (Fig. 5 línea superior). El porcentaje de ilita presente puede aproximarse con mirar la posición de la refleción cerca de 16 a $17^{\circ} 2 \theta$ (Moore y Reynolds, Jr. 1997). Una distancia d=5.11 $/ 2 \theta$ $=17,34^{\circ}$ sugiere que el porcentaje de ilita en los niveles mixtos de ilita/esmectita sobrepasa los $90 \%$, lo cual apunta a una ilita para la arcilla de Sangal.

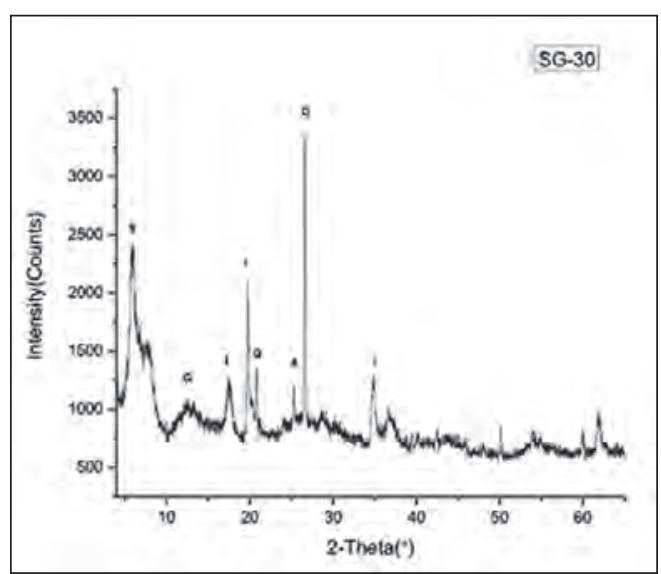

Figura 4. Difractograma para la arcilla SG30, análisis global, agregados con orientación variable (randomly oriented aggregates). $S$ esmectita, C/K clorita/caolinita, I ilita, Q cuarzo, A anatasa.

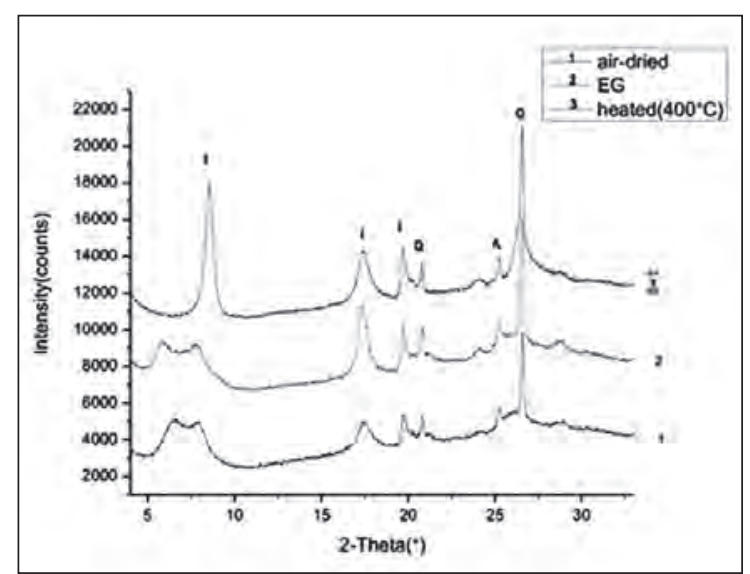

Figura 5. Difractograma para la arcilla SG30, análisis de los minerales arcillosos, agregados orientados, tratamiento EG y $400{ }^{\circ} \mathrm{C}$. I ilita, Q cuarzo, A anatasa.

Arcillas MA22, MA25 y MM14b de Mangallpa

Los dos difractogramas para las arcillas MA22 y MA25 de Mangallpa son similares, con una composición arcillosa mayoritaria de ilita y esmectita. Como fase menor, un pico de clorita se superpone a otro que podría ser de caolín pero es más probable que la clorita esté el mineral presente en estas muestras. La muestra MM14b colectada en 2012 contiene solamente esmectita.

\section{Arcilla JA1 de Jangalá}

A parte de los picos para plagioclasa y cuarzo, no se distinguen bien los picos de los minerales arcillosos, indicando una composición poca arcillosa.

\section{Temperante de arena JA2 de Jangalá}

Dos tipos de plagioclasas son presentes con picos (002) a d=3,21 $\AA$ y d=3,19 $\AA$. El análisis petrográfico determinó que eran plagioclasas sódicas tipo oligoclasa y andesina. El pico a d=7,17 ̊̊ puede indicar la presencia de clorita o ilita, mientras que el pico a $d=14,69 \AA ̊$ indica la presencia de clorita y esmectita. Sin embargo, estos picos son menores comparativo a los picos de cuarzo y plagioclasa. 


\section{b) IDENTIFICACIÓN DE LA PRESENCIA DE MANGANESO}

La muestra de manganeso en polvo dada por el ceramista Lorenzo Cabrera se identifica como una todorokite de composición $\mathrm{NaMn}_{6} \mathrm{O}_{12} 3 \mathrm{H}_{2} 0$. Para identificar la presencia de manganeso en los fragmentos de cerámica arqueológica, 17 óxidos de manganesos fueron utilizados como referencia para identificar los picos en los difractogramas. Sin embargo, ninguna de las seis muestras analizadas reveló una presencia significativa de manganeso.

\section{RESULTADOS DE LOS ANÁLISIS DE LAS ARCILLAS POR ESPECTROSCOPÍA}

Las cuatro muestras procedentes del valle medio del Jequetepeque MTJ3, MTJ4, MTJ5 y MTJ10 (Cuadro 1) contienen todas caolín y esmectita. La muestra MTJ10 de un canal de riego cerca del sitio arqueológico de La Bomba contiene además ilita. La muestra de mezcla cruda de Mangallpa sólo tiene ilita.

\section{RESUlTAdos DEL ANÁLISIS PETROGRÁFICO DEL MATERIAL COMPARATIVO ${ }^{4}$}

Se analizaron muestras de arcillas, temperantes, líticos y fragmentos de vasijas modernas. El cuadro 3 presenta una síntesis de los resultados del análisis petrográfico de las muestras en relación con este estudio. Los resultados integran la discusión en la sección siguiente. Las figuras 6 y 7 ilustran el tipo de pasta cerámica para la zona de Mangallpa y Jangalá, y la figura 8 ilustra la pasta de una cerámica arqueológica con temperante volcánico. A continuación se presenta también un resumen de los resultados del análisis petrográfico del material arqueológico.
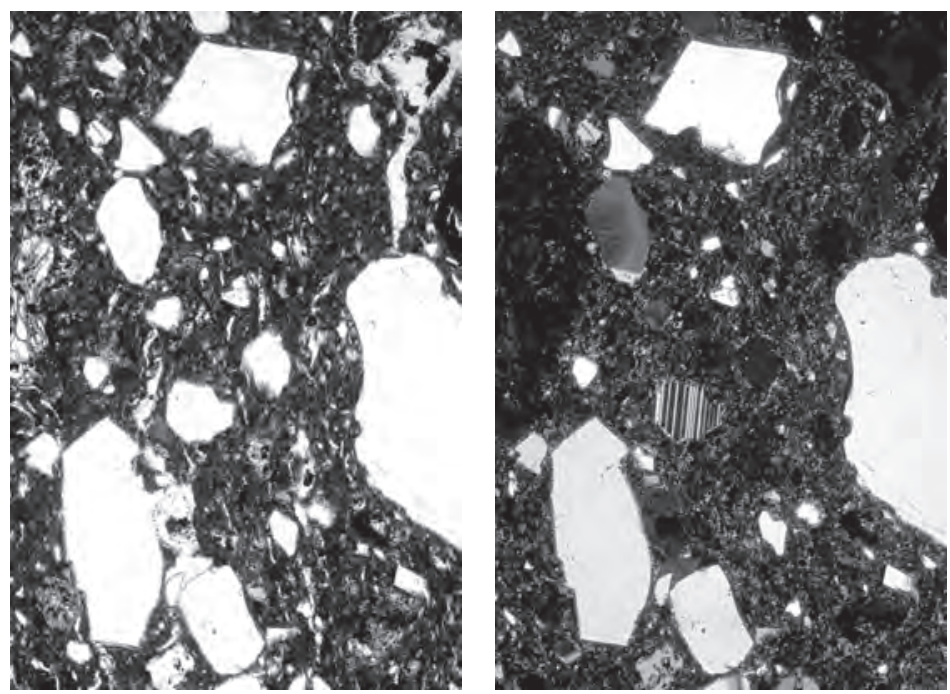

Figura 6. Fotomicrografía de pasta de una olla de Mangallpa MA27, a) luz natural polarizada, b) luz polarizada cruzada. Toba vidriada, cristales de cuarzo, plagioclasa y biotita. Ancho de foto $2,25 \mathrm{~mm}$.

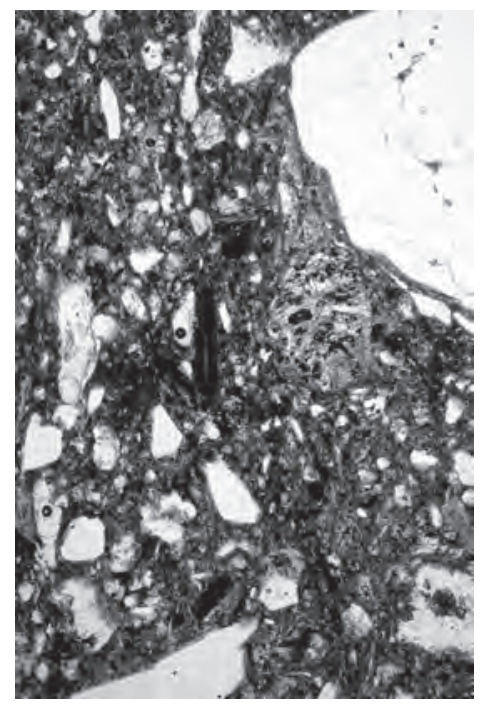

Figura 7. Fotomicrografía de pasta de cazuela de Llapa Ll32. Luz natural polarizada. Vidrio volcánico, toba soldada, cristales de cuarzo, plagioclasa y biotita. Ancho de foto $2,25 \mathrm{~mm}$.

4 El análisis petrográfico fue hecho por Isabelle Druc en el laboratorio de petrografía del departamento de Geociencias de la Universidad de Wisconsin-Madison, con un microscopio petrográfico Leitz. Las fotomicrografías se tomaron con un microscopio Nikon con cámara digital en la oficina del Dr. Stoltman en el departamento de Antropología de la Universidad de Wisconsin-Madison. 

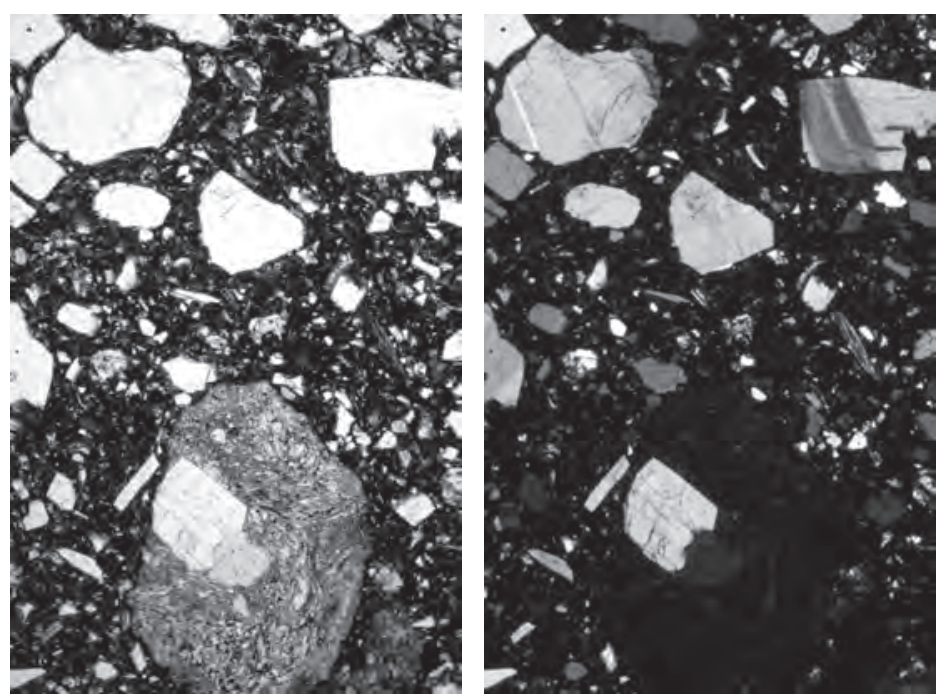

Figura 8. Fotomicrografía de pasta felsica-volcánica de cerámica de Kuntur Wasi, Petrogrupo A, lámina CP59, fase Copa. a) luz natural polarizada,

b) luz polarizada cruzada. Inclusiones piroclásticas, toba soldada, cristales de cuarzo, plagioclasa, feldespato potásico y mica. Ancho de foto 2,25 $\mathrm{mm}$.

Cuadro 3. Síntesis del análisis petrográfico de las muestras comparativas

\begin{tabular}{|c|c|c|c|}
\hline Muestras & Tipos/ORIGEN & FASES MAYORES & FASES MENORES \\
\hline SG30* & Arcilla Sangal. & Arcilla. & $\begin{array}{l}\text { Cuarzo grueso }<2 \% \\
\text { Arenisca gruesa }<2 \%\end{array}$ \\
\hline MA22 & $\begin{array}{l}\text { Arcilla } \\
\text { Mangallpa. }\end{array}$ & $\begin{array}{l}\text { Cuarzo muy fino* } \\
\text { feldespatos alterados. }\end{array}$ & $\begin{array}{l}\text { Micas volcánicos medianos } \\
\text { con textura traquítica opa- } \\
\text { cas, hematitas. }\end{array}$ \\
\hline $\begin{array}{l}\text { MA23 y } \\
\text { MA26 }\end{array}$ & $\begin{array}{l}\text { Temperantes } \\
\text { Mangallpa. }\end{array}$ & $\begin{array}{l}\text { Volcánicos }>50 \% \text { (piroclásticos, } \\
\text { granos criptocristalinos, toba } \\
\text { soldada, vidrio, traquita), plagio- } \\
\text { clasa fina a gruesa tipo andesita } \\
\text { a labradorita cuarzo de origen } \\
\text { volcánica. }\end{array}$ & $\begin{array}{l}\text { Biotita minerales opacos } \\
\text { óxidos Fe/Ti epidota }<2 \% \\
\text { arenisca muy gruesa mica } \\
\text { blanca (MA23) ortopiroxe- } \\
\text { no fino (MA23). }\end{array}$ \\
\hline $\begin{array}{l}\text { MA24 y } \\
\text { MA27 }\end{array}$ & $\begin{array}{l}\text { Fragmentos de } \\
\text { ollas modernas } \\
\text { de Mangallpa. }\end{array}$ & $\begin{array}{l}\text { Toba soldada, vidrio, granos } \\
\text { criptocristalinos, plagioclasa zo- } \\
\text { nada tipo albita, cuarzo. }\end{array}$ & $\begin{array}{l}\text { Biotitas, minerales opacos, } \\
\text { minerales fero-magnesia- } \\
\text { nos y raros cristales de pi- } \\
\text { roxeno. }\end{array}$ \\
\hline MM14a & $\begin{array}{l}\text { Pasta prepara- } \\
\text { da Sr. Alvito, } \\
\text { Mangallpa. }\end{array}$ & $\begin{array}{l}\text { Composición volcánica con cuar- } \\
\text { zos angulosos, plagioclasas. }\end{array}$ & Vidrio soldado. \\
\hline MM14b & $\begin{array}{l}\text { Arcilla } \\
\text { Sr. Alvito, } \\
\text { Mangallpa. }\end{array}$ & Arcilla. & $\begin{array}{l}\text { Cuarzos finos, raros frag- } \\
\text { mentos finos de cuarcita. }\end{array}$ \\
\hline \multicolumn{4}{|c|}{$\begin{array}{l}\text { * Láminas preparadas a partir de tiestos hechos con arcilla de Sangal, quemados a } 500^{\circ} \mathrm{C} \text { y } 900^{\circ} \mathrm{C} \text {. } \\
\text { ** Las clases granulométricas siguen la escala de Udden-Wentworth, en Folk, } 1965 \text { (límite superior } \\
\text { de la clase): arcilla }<0,002 \mathrm{~mm} \text {, limo }<0,0625 \mathrm{~mm} \text {, arena muy fina a fina } 0,25 \mathrm{~mm} \text {, arena mediana } \\
0,50 \mathrm{~mm} \text {, arena gruesa } 1 \text {, arena muy gruesa } 2 \mathrm{~mm} \text {. }\end{array}$} \\
\hline
\end{tabular}




\begin{tabular}{|c|c|c|c|}
\hline Muestras & TIPOS/ORIGEN & FASES MAYORES & FASES MENORES \\
\hline MM15 & $\begin{array}{l}\text { Arena, Jancos } \\
\text { Alto. }\end{array}$ & $\begin{array}{l}\text { Fragmentos subvolcánicos de } \\
\text { tipo dacita, alterados, subredon- } \\
\text { dos, de talla media a muy gruesa. }\end{array}$ & $\begin{array}{l}\text { Minerales sueltos proce- } \\
\text { dentes de los fragmentos } \\
\text { subvolcánicos. }\end{array}$ \\
\hline JA1 & Arcilla Jangalá. & $\begin{array}{l}\text { Folletos de mica en la matriz } \\
\text { arcillosa. }\end{array}$ & $\begin{array}{l}\text { Conglomerados }<2 \% \text { media- } \\
\text { nos con microcuarzo y fel- } \\
\text { despatos. }\end{array}$ \\
\hline JA2 & $\begin{array}{l}\text { Temperante } \\
\text { Jangalá. }\end{array}$ & $\begin{array}{l}\text { Cuarzo fino a mediano plagio- } \\
\text { clasa sódica tipo oligoclasa a an- } \\
\text { desina (An } 20-30 \% \text { ). }\end{array}$ & $\begin{array}{l}\text { Cuarzo grueso cuarcita } \\
\text { mediana volcánicos finos } \\
\text { a medianos (toba soldada } \\
\text { y granos criptocristalinos) } \\
\text { micas, opacas }<2 \% \text {. }\end{array}$ \\
\hline JA4 & Jarrita Jangala. & $\begin{array}{l}\text { Volcánicos (piroclásticos, granos } \\
\text { criptocristalinos, toba soldada, } \\
\text { vidrio, traquita), plagioclasa fina } \\
\text { a gruesa cuarzo de origen volcá- } \\
\text { nica, biotita. }\end{array}$ & $\begin{array}{l}\text { Granos finos de alta birefri- } \\
\text { gencia, minerales opacos y } \\
\text { piroxenos. }\end{array}$ \\
\hline JA5 & $\begin{array}{lr}\text { Fragmento } & \text { de } \\
\text { olla de } & \text { estilo } \\
\text { Mangallpa } & \text { (en- } \\
\text { contrada } & \text { en } \\
\text { Jangala). } & \end{array}$ & $\begin{array}{l}\text { Piroclásticos, granos criptocris- } \\
\text { talinos, toba soldada, vidrio, tra- } \\
\text { quita, plagioclasa fina a gruesa } \\
\text { tipo andesita a labradorita } \\
\text { cuarzo. }\end{array}$ & $\begin{array}{l}\text { Biotitas, minerales opacos, } \\
\text { minerales fero-magnesia- } \\
\text { nos y raros cristales de pi- } \\
\text { roxeno. }\end{array}$ \\
\hline Li32 & $\begin{array}{l}\text { Fragmento de } \\
\text { cazuela, Jancalá/ } \\
\text { Llapa. }\end{array}$ & $\begin{array}{l}\text { Volcánicos (piroclásticos, granos } \\
\text { criptocristalinos, toba soldada, vi- } \\
\text { drio, traquita), plagioclasa fina a } \\
\text { gruesa cuarzo de origen volcánica, } \\
\text { biotita. }\end{array}$ & $\begin{array}{l}\text { Granos finos de alta zirefri- } \\
\text { gencia, minerales opacos y } \\
\text { piroxenos. }\end{array}$ \\
\hline MKW18 & $\begin{array}{l}\text { Arena de la que- } \\
\text { brada Sangal ca. } \\
1 \mathrm{~km} \text { al sur de } \\
\text { Kuntur Wasi. }\end{array}$ & $\begin{array}{l}\text { Composición sedimentaria con } \\
\text { aterial de origen volcánico, orto- } \\
\text { cuarcita, toba con cuarzos finos } \\
\text { a gruesos, feldespatos alterados. }\end{array}$ & $\begin{array}{l}\text { Cuarcita de bajo metamor- } \\
\text { fismo, plagioclasa, granos } \\
\text { de textura traquítica, un } \\
\text { microcarbonato. }\end{array}$ \\
\hline Li1 & Roca Sangal. & $\begin{array}{l}\text { Plagioclasa muy alterada, } \\
\text { feldespatos, cuarzo, fino a muy } \\
\text { grueso. }\end{array}$ & $\begin{array}{l}\text { Carbonatos gruesos traqui- } \\
\text { ta, vidrio alterado, recris- } \\
\text { talización y alteración en } \\
\text { el borde de micas blancas y } \\
\text { anfíbolas. }\end{array}$ \\
\hline MTJ10 & $\begin{array}{l}\text { Arcilla de un } \\
\text { canal de rie- } \\
\text { go, La Bomba, } \\
\text { Jequetepeque. }\end{array}$ & $\begin{array}{l}40 \% \text { limon y cristales felsicos } \\
\text { muy finos. }\end{array}$ & $\begin{array}{l}10 \% \text { cristales de talla media } \\
\text { a gruesa y litoclastos subre- } \\
\text { dondos de cuarcita, grano- } \\
\text { diorita, pelita, limolita y } \\
\text { granos poiquilíticos de bajo } \\
\text { metamorfismo. }\end{array}$ \\
\hline
\end{tabular}

El cuadro 4 presenta un resumen de los resultados del análisis petrográfico de las muestras arqueológicas, informaciones que sirven para valorar los datos comparativos y la discusión sobre los resultados de análisis. Los petrogrupos se distinguen entre si por su composición lítica mayoritaria. Sin embargo, existe una variabilidad composicional dentro de cada petrogrupo que permite ver tendencias por fases arqueológicas, estilos y formas de vasijas. Ciertos sub-grupos apuntan a tradiciones tecnológicas de producción cerámica que indican la existencia de distintos centros de producción o grupos productores. 
Cuadro 4: Resumen de los datos petrográficos para las cerámicas arqueológicas

\begin{tabular}{|c|c|c|c|}
\hline Petrogrupo & COMPONENTES MAYORES & COMPONENTES MENORES & OBSERVACIONES \\
\hline $\begin{array}{l}\text { A Composición } \\
\text { felsica-volcá- } \\
\text { nica }(n=43 / 88 \\
48,88 \%)\end{array}$ & $\begin{array}{l}\text { Minerales felsicos suban- } \\
\text { gulares (cuarzo, feldespato } \\
\text { alcalino y plagioclasa sódica } \\
\text { tipo andesina) de talla fina a } \\
\text { gruesa fragmentos redondos } \\
\text { volcánicos criptocristalinos, } \\
\text { traquitas, piroclásticos, toba } \\
\text { y toba soldada, vidrio, frag- } \\
\text { mentos de andesita. }\end{array}$ & $\begin{array}{l}\text { Fragmentos de origen } \\
\text { sedimentaria (cuar- } \\
\text { citas y areniscas) que } \\
\text { pueden presentar un } \\
\text { principio de metamor- } \\
\text { fismo cristales finos de } \\
\text { biotita, hornablenda u } \\
\text { otra anfíbol, y óxidos. }\end{array}$ & $\begin{array}{l}20 \text { a } 50 \% \text { de inclusio- } \\
\text { nes. La pasta puede } \\
\text { ser cuasi opaca, iso- } \\
\text { trópica. }\end{array}$ \\
\hline $\begin{array}{l}\text { B Composición } \\
\text { de roca intru- } \\
\text { siva interme- } \\
\text { dia }(n=27 / 88 \\
30,68 \%) .\end{array}$ & $\begin{array}{l}\text { Fragmentos de granodiorita, } \\
\text { tonalita y/o diorita, plagio- } \\
\text { clasas y feldespatos alcali- } \\
\text { nos, minerales máficos en la } \\
\text { pasta y los fragmentos líti- } \\
\text { cos: hornablenda, que puede } \\
\text { ser muy frecuente, y biotita. }\end{array}$ & $\begin{array}{l}\text { Piróxenos } \quad \text { (cpx). } \\
\text { Minerales opacos } \\
\text { fragmentos finos vol- } \\
\text { cánicos en la matriz } \\
\text { arcillosa. }\end{array}$ & $\begin{array}{l}20 \text { a } 60 \% \text { de inclusiones } \\
\text { composiciones varia- } \\
\text { bles según las láminas, } \\
\text { distribución bimodal } \\
\text { (volcánicos o cuarzos } \\
\text { finos vs. intrusivos } \\
\text { medianos a gruesos), } \\
\text { alteración de los fel- } \\
\text { despatos. }\end{array}$ \\
\hline $\begin{array}{l}\text { C Composición } \\
\text { volcánica } \\
(\mathrm{n}=6 / 88,6,81 \\
\%) .\end{array}$ & $\begin{array}{l}\text { Fragmentos piroclásticos y } \\
\text { criptocristalinos subredon- } \\
\text { dos, vidrio y minerales felsi- } \\
\text { cos ubangulares a subredon- } \\
\text { dos talla mediana a gruesa. }\end{array}$ & $\begin{array}{l}\text { Pocos minerales máfi- } \\
\text { cos, de talla fina. }\end{array}$ & $\begin{array}{l}20 \text { a } 35 \% \text { de inclusio- } \\
\text { nes, } 50 \% \text { para KW20. }\end{array}$ \\
\hline $\begin{array}{l}\text { D Composición } \\
\text { mixta } \\
(n=12 / 88 \\
13,63 \%)\end{array}$ & $\begin{array}{l}\text { Fragmentos de roca sedi- } \\
\text { mentaria, volcánica, y me- } \\
\text { tamórfica con cuarcitas, } \\
\text { areniscas, metacuarcitas y } \\
\text { pelitas. }\end{array}$ & $\begin{array}{l}\text { Algunos fragmentos in- } \\
\text { trusivos subredondos en } \\
\text { ciertas laminas fragmen- } \\
\text { tos redondos volcánicos, } \\
\text { traquitas y criptocrista- } \\
\text { les. }\end{array}$ & $\begin{array}{l}20 \text { a } 40 \% \text { de inclusio- } \\
\text { nes, } 50 \% \text { para KW } 40 \text {. }\end{array}$ \\
\hline
\end{tabular}

\section{Discusión}

\section{DISPONIBILIDAD DE ARCILLAS PARA LA PRODUCCIÓN CERÁMICA CERCA DEL CENTRO CEREMONIAL DE KUNTUR WASI}

El color blanco y la plasticidad de la arcilla de Sangal (SG30) a primera vista sugería la presencia de caolín, un material muy utilizado en la producción cerámica en el Intermedio temprano en la sierra norcentral andina, en particular en las cerámicas de Recuay y Cajamarca. Cabe notar que Cajamarca está sólo a unos $30 \mathrm{~km}$ al este de Kuntur Wasi y que cerámicas de estilo Cajamarca se encuentran en la mayor parte de la región de Cajamarca. Sara Moller, una ceramista en Madison, Wisconsin, observó que al trabajar la arcilla, las vetas de color marrón de óxido de hierro desaparecían y que se homogeneizaba el material al color blanco. Sin embargo, al quemar un tiesto experimental, primero a fuego abierto (circa $500-600^{\circ} \mathrm{C}$ ), luego en un horno eléctrico $\left(900^{\circ} \mathrm{C}\right.$ ), el color blanco desaparece y la pasta adquiere un color marrón anaranjado. Eso no corresponde al comportamiento del caolín que suele quemarse en blanco. Como comprobación, el análisis con DRX no reveló picos de caolín en la muestra, sino picos de ilita. 
Se notó que la ilita puede ser de color blanco a gris cuando no está quemada, y la pasta puede pasar de anaranjado a marón según el porcentaje de óxido de hierro cuando se quema en atmosfera oxidante. La arcilla de Sangal no se utiliza actualmente, pero puede haber servido para la producción de cerámica antigua. Varias cerámicas encontradas en Kuntur Wasi tienen una pasta marrón. Una comparación directa con la fase arcillosa de las cerámicas es difícil, pero la proximidad de esta arcilla al sitio arqueológico la designa como una posible fuente de material. Debemos también mencionar la presencia de caolín y montmorillonita en los alrededores del pueblo de Sangal al sur de Kuntur Wasi según el estudio geológico de Shinsuke Yomoda (2002: 82). Un próximo estudio deberá verificar el extenso de tales fuentes. Sin embargo, la mayoría (>75\%) de la cerámica de Kuntur Wasi tiene una pasta de color oscuro a negro. Esto puede resultar de una quema reductora o de adición de manganeso. Los análisis con DRX sin embargo, demostraron que ninguna de las cerámicas analizadas tiene este mineral en porcentaje suficiente como para dar el color negro a la pasta.

Las muestras LA28 provenientes de una laguna a tres kilómetros de Kuntur Wasi y la arcilla SP29 del pueblo de San Pablo a dos kilómetros no son materiales suficiente arcillosos para ser utilizados para la producción cerámica.

\section{ARCILLAS DE MANGALLPA}

Dos arcillas de Mangallpa muestran una composición muy similar, aunque fueron recolectadas en dos lugares distintos del pueblo por dos alfareros diferentes. No se puede generalizar a partir de dos muestras, pero el análisis sugiere que estas fuentes pertenecen al mismo depósito y que son bastante homogéneas. La tercera muestra MM14b parece más pura y tiene solamente esmectita. El análisis petrográfico reveló que las muestras de arcilla de Mangallpa MA22 y MM14b tienen inclusiones finas, con pocas impuridades, minerales o granos félsicos, al contrario de la muestra de Sangal, la cual tiene inclusiones gruesas de cuarzo y arenisca cuarzosa. La arcilla de Mangallpa es abundante y ha sido explotada por generaciones de alfareros. Estas observaciones favorecen una producción en, o con material de, Mangallpa en tiempos antiguos.

\section{LAS FUENTES DE JANGALÁ}

De modo sorprendente, la arcilla dada por un alfarero de Jangalá no resultó tener una composición muy arcillosa, pero minerales arcillosos aparecieron en la composición de la arena colectada en un corte de camino a unos 500 metros de la casa del alfarero y que es usada en su mezcla. Este temperante tiene clorita, ilita y/o esmectita, además de las inclusiones no arcillosas y fragmentos volcánicos. Debemos concluir que la plasticidad de la pasta proviene de la combinación de las dos materias primas. Además, el análisis petrográfico reveló que los materiales utilizados para la producción en Jangalá tienen una composición más máfica que en la zona de Mangallpa. Cabe notar que los cuerpos intrusivos (y sedimentos derivados) cerca de San Miguel de Pallaques tienen una composición más máfica que los cuerpos más al sur (Pedro Navarro, comunicación personal agosto 2011).

\section{TEMPERANTES}

El temperante utilizado en la producción actual de Mangallpa, con su composición volcánica, toba soldada, vidrio, cuarzo y plagioclasa corresponde bien al tipo de inclusiones encontradas en muchas de las cerámicas arqueológicas de Kuntur Wasi. En particular, se comparan al temperante de las cerámicas de los Petrogrupos A y C caracterizados por un temperante felsico volcánico y con estilos decorativos en gran parte locales. Representan más de 55,69\% de las cerámicas analizadas de Kuntur Wasi. El petrogrupo D con temperante mixto, que representa un $14,77 \%$ del corpus arqueológico analizado incluye mayoritariamente fragmentos volcánicos y sedimentarios y puede resultar del uso de material local o proveniente de la zona de Mangallpa. Las muestras de roca Li1, la arcilla de Sangal SG30 
y arena MM15, los temperantes modernos Ma23 y MA26, todos contienen fragmentos sedimentarios y metamórficos que son similares a lo visto en las cerámicas arqueológicas del petrogrupo D. Estas composiciones concuerdan con los sedimentos geológicos locales.

Un temperante volcánico similar a lo de Mangallpa se encuentra en la cerámica moderna de Jangalá. Sin embargo, esta área de producción -y de fuentes- está ubicada más lejos de Kuntur Wasi que las fuentes de Mangallpa (16 km en comparación a $8 \mathrm{~km}$ ). Debido a esto, es poco probable que la zona de Jangalá haya sido el origen de muchas cerámicas encontradas en Kuntur Wasi.

Finalmente, la composición de la muestra de roca de Sangal, con fragmentos de carbonatos y cuarcitas, corresponde a la composición local de la formación Chulec del Cretáceo inferior. Esta formación está clasificada como un sedimento clástico con calizas arenosas, lutitas calcáreas y margas (Reyes Rivera 1980). La muestra viene de un corte en la carretera, al sur del Cerro Las Copas donde se encuentra Kuntur Wasi. Además la presencia de material volcánico y posiblemente de minerales recristalizados e inclusiones con bajo metamorfismo apunta a una roca consolidada con material sedimentario y volcánico. Tenemos que subrayar que solamente 2 de los 88 fragmentos de cerámica arqueológica tienen algunos carbonatos en su pasta. La ocurrencia muy baja de estas inclusiones nos hace descartar la hipótesis del uso de esta roca como temperante en la producción cerámica local, pero se puede que otros afloramientos de la formación Chulec corresponda mejor a la composición de las cerámicas del Petrogrupo D de Kuntur Wasi.

\section{ARCILLAS: DIFERENCIAS AL NIVEL REGIONAL}

Según los análisis DRX y de espectroscopía se observa que las muestras arcillosas provenientes del valle medio del Jequetepeque tienen caolín (además de esmectita), mientras que las muestras de la región de Kuntur Wasi no (pero tienen ilita y esmectita). Este punto es de importancia para discriminar la procedencia de materiales al nivel regional. Sin embargo, el problema para caracterización cerámica es: 1 . La dificultad de comparar arcilla cruda con un material mezclado y quemado a temperaturas que destruyen la red cristalina de los minerales arcillosos, en particular caolín que es afectado pasando los $550^{\circ} \mathrm{C} ; 2$. De poder analizar la fase arcillosa (sin inclusiones o temperante) de una cerámica. El primer problema podría superarse si se logra observar mulita o espinela en DRX, que pueden proceder de la transformación de caolín a temperaturas entre $900^{\circ} \mathrm{C}$ y $1100^{\circ} \mathrm{C}$. Pero no es fácil aislar la fase arcillosa de una cerámica para análisis con DRX y las cerámicas andinas antiguas normalmente no fueron quemadas a tan alta temperatura (Wagner et al. 1988). El segundo problema se resuelva con microscopio electrónico de barrido con análisis puntual focalizando el rayo de electrones en una área libre de inclusiones, pero no permite igualar fácilmente los resultados a una fase mineral (caolín). ${ }^{5}$

\section{MANGANESO}

Los análisis dirigidos a detectar la presencia de manganeso en la cerámica arqueológica dieron resultados negativos. Por lo tanto, el color negro de muchas pastas de Kuntur Wasi no parece resultar de una adición de manganeso. Más bien, el color del cuerpo debe ser producto del tipo de arcilla (quemando a negro) o de las condiciones de quema en relación con el acceso al oxígeno, una oxidación incompleta de los materiales orgánicos, la duración de la quema o el combustible utilizado. Estudios con análisis Mössbauer de cerámicas de otros sitios formativos nor-andinos, como Montegrande, Batan Grande y Huacaloma, muestran que una quema reductora era muy común (Wagner et al. 1988).

5 Para una discusión sobre análisis de arcillas con DRX y MEB ver Bertolino y Fabra (2003) o Bertolino et al. (2009). 


\section{PROCESOS DE ADQUISICIÓN DE LAS MATERIAS PRIMAS}

El estudio etnográfico hecho en la región de San Pablo muestra que los alfareros de Mangallpa son itinerantes dos a tres meses por año y que la producción en Mangallpa abastece toda la zona (Druc 2011). Cuando salen a producir, los alfareros llevan con ellos sus materiales, lo que significa que aunque se produzcan lejos de Mangallpa, las vasijas tienen la composición mineral típica de Mangallpa. Tal situación puede haber sucedido en el pasado, ya que la costumbre de itinerancia de los artesanos es antigua (Ramón 2011). Asimismo, el material de la zona de Mangallpa-Cuscuden pudo haber sido utilizado por alfareros en Kuntur Wasi.

Vale mencionar aquí que las fuentes más cercanas al lugar de producción no son necesariamente las que se utilizan y que los sistemas de intercambios pueden ser basados en vínculos sociales o culturales, y no tanto en lazos estrictamente económicos (Arnold 2005; Miksa 1998). Añadiremos el ejemplo del alfarero Manuel Hernández Suárez que se mudó de la región de San Miguel a Cerro Blanco, a un kilómetro de Kuntur Wasi, pero que seguía buscando sus arcilla y temperante en las fuentes del cerro Cuscuden, como lo hacía su familia anteriormente, lo cual implicaba un viaje de cinco horas para él (Druc 2011). También podemos aludir al análisis de la cerámica de Montegrande que revela la presencia de un alto porcentaje de vasijas utilitarias con pasta alógena, casi en equilibrio cuantitativo con la cerámica local (Ulbert 1994: 137). Esto indica que las vasijas utilitarias aúnque abundantes en un sitio no garantizan su caracter local.

Estos ejemplos apuntan a procesos poco considerados cuando se interpretan los datos de análisis de cerámica. En el caso de Kuntur Wasi, tales procesos no pueden ser olvidados. Un tercio de la cerámica presenta un temperante intrusivo que en parte no es local, y el resto tiene composiciones correspondientes a la geología local y regional, con temperante volcánico tal como se utiliza todavía en la producción tradicional actual. Sin embargo, variaciones minerales y de textura en las pastas arqueológicas sugieren la existencia de múltiples talleres, lugares de producción o fuentes, y/o el uso de diferentes recetas. Además se nota un cambio de tradición tecnológica para parte de la producción cerámica en la fase Copa, cuando se registra la mayor expansión del sitio.

\section{ConClusión}

La caracterización de las muestras comparativas de la zona de Kuntur Wasi, Mangallpa, Jangalá y del valle medio del Jequetepeque nos proveyó de varias informaciones importantes para interpretar los datos arqueológicos en relación con la producción cerámica antigua. La arcilla de Sangal, la más cercana al sitio arqueológico, es una ilita, y no caolín como anteriormente se pensaba. La ceramista Sara Moller demostró que se podía utilizar para la producción cerámica, aún sin temperante y que resultaba en una pasta beige marrón a la quema. Es posible que fuera utilizada en tiempos antiguos, pero para una producción reducida, ya que muchas de las cerámicas tienen un cuerpo de otro color. El cuerpo negro de muchas cerámicas no proviene de la adición de manganeso, como se comprobó en los análisis, sino que debe resultar del uso de una arcilla que se vuelve negra a la quema o debido a las condiciones de quema. Los análisis rechazaron la posibilidad de uso de la arcilla de San Pablo y de La Laguna, no teniendo bastante material arcilloso. Los materiales de Mangallpa, sin embargo son de buena calidad y abundantes tanto en arcilla como temperante.

La similitud del temperante volcánico de Mangallpa con el material observado en muchas láminas de cerámica arqueológica de Kuntur Wasi nos permite designar a esta región como un candidato serio para la producción en la antigüedad. Asimismo, el proceso de recolectar muestras comparativas permitió descubrir una fuente non sospechada de material subvolcánico en un sedimento a unos $10 \mathrm{~km}$ del centro ceremonial. Esto podría explicar la presencia de fragmentos subvolcánicos en ciertas cerámicas de Kuntur Wasi de la fase Copa que tienen un carácter estilístico local. La tradición actual de alfareros itinerantes ofrece otro escenario posible para la obtención de vasijas en Kuntur Wasi, las cuales pueden 
haber sido hechas in-situ, pero con material de Mangallpa. En cuanto al fragmento de roca sedimentaria colectada cerca del centro ceremonial, este no corresponde a composiciones observadas en las cerámicas arqueológicas, eliminando este material como fuente potencial de temperante. Finalmente, el análisis de las arcillas reveló que el caolín caracteriza las muestras arcillosas del valle medio del Jequetepeque pero o se nota en las muestras analizadas de la zona de Kuntur Wasi.

Los análisis de difracción de rayos X y de petrografía de las muestras comparativas ofrecen una base para la interpretación de los datos cerámicos en Kuntur Wasi, en particular relativo a la posibilidad de producción in-situ. Al ser triangulados con los estudios etnográficos, los resultados presentan una visión más clara de las fuentes disponibles alrededor de Kuntur Wasi. Es probable que los materiales utilizados para producir una mayor cantidad de las cerámicas con temperante volcánico eran extraídos de la falda del cerro Cuscuden, ubicado relativamente cerca a Kuntur Wasi. Los ocho a diez kilómetros que separan el sitio arqueológico de estas fuentes o de Mangallpa como zona posible de producción todavía se ubican dentro del rayo de explotación de materias primas alrededor de un centro productor (Arnold 1985). Esto técnicamente define lo que es local. Ahora falta identificar lo que no lo es y su procedencia. Estudios comparativos de cerámicas de sitios en el valle central del Jequetepeque y en Cajamarca serán el objeto de otros análisis para tener una mejor idea de la distribución de la cerámicas al nivel regional y de las posibles relaciones de intercambio entre sitios vecinos.

\section{Agradecimientos}

Este estudio se llevó a cabo gracias al apoyo económico de la Saitama University, en Japón, tanto para el trabajo de campo, como para el análisis de la cerámica. El proyecto Kuntur Wasi proveyó el alojamiento y el transporte a lugares de difícil acceso. En la Universidad de Wisconsin-Madison, en el Departamento of Geociencias, agradecemos el apoyo del Dr. Huifang Xu, quien nos permitió trabajar en el laboratorio de difracción de rayos X, y la ayuda del Dr. John Valley, quien facilitó el acceso al laboratorio de petrografía. El Dr. Jim Stoltman, del departamento de Antropología en la misma universidad, nos dejó utilizar su microscopio para sacar las fotomicrografías. En Lima, queremos agradecer a Pedro Navarro Colque, Víctor Carlotto Caillaux y Elizabeth Ordoñez López del INGEMMET en Lima. Sus consejos y apoyo técnico fueron de gran ayuda para este proyecto. Finalmente agradecemos a Sara Moller, ceramista, quien experimentó con la arcilla de Sangal. 


\section{BiBLIOGRAFÍA}

ARNOLD, Dean E.

1985 Ceramic theory and cultural process. Cambridge: Cambridge University Press.

BERTOLINO, Silvana y M. FABRA

2003 «Provenance and ceramic technology of pot sherds from ancient Andean cultures at the Ambato valley, Argentina». Applied Clay Science 24: 21-34.

BERTOLINO, Silvana, V. GALVÁN JOSA, A. C. CARRERAS, A LAGUENS, G. DE LA FUENTE, y J. A. RIVEROS

2009 «X-ray techniques applied to surface paintings of ceramic pottery pieces from Aguada Culture (Catamarca, Argentina)». X-Ray Spectrometry 38: 95-102.

BRINDLEY, G. W. y G. BROWN

1980 Crystal structures of clay minerals and their X-ray identification. Londres: Mineralogical Society.

CLARK, Kenneth

2001 The potter's manual. Edison: Chartwell Books.

DRUC, Isabelle

2011 «Tradiciones alfareras del valle de Cajamarca y cuenca alta del Jequetepeque, Perú». En Bulletin de l'Institut Français d'Études Andines, 40(2): 307-331. Lima.

DRUC, I., K. INOKUCHI, C. CARLOTTO y P. NAVARRO

2013 «Looking for the right outcrop». En: M. Ownby, M. Masucci e I. Druc (eds.) Integrative Approaches in Ceramic Petrography. Salt Lake City: University of Utah Press.

FOLK, R.L.

1965 Petrology of sedimentary rocks. Austin: The University of Texas.

GRATHOFF, G. H. y D. M. MOORE

1996 «Illite polytype quantification using WILDFIRE calculated X-ray diffraction patterns». En: Clays and Clay Minerals 44: 835-842.

INOKUCHI, Kinya

1998 «La cerámica de Kuntur Wasi y el problema Chavin». En: Boletín de Arqueología Pontificia Universidad Católica del Perú (PUCP) 2:161-180.

2010 «La arquitectura de Kuntur Wasi: secuencia constructiva y cronología de un centro ceremonial del Periodo Formativo». En: Boletín de Arqueología, Pontificia Universidad Católica del Perú (PUCP) 12: 219-248.

MIKSA, Elizabeth

1998 A model for assigning temper provenance to archaeological ceramics with case studies from the American Southwest. Tesis de doctorado, Department of Geosciences, University of Arizona, Tucson.

MOORE, D. M. y R. C. REYNOLDS Jr.

1997 X-ray diffraction and the identification and analysis of clay minerals. New York: Oxford University Press.

NAVARRO, P. y C. FLORES

2007 Mapa geológico del cuadrángulo de Cajamarca, hoja 15-f-IV, 1:50,000. Lima: INGEMMET.

NAVARRO, Pedro

2008 Mapa geológico del cuadrángulo de Chota, hoja 14-f-III, 1:50,000.

INGEMMET

2011 Mapa geológico del cuadrángulo de Chepén, hoja 15-e, 1:50,000. Lima: INGEMMET.

NAVARRO, P., R. MONGE y A. FLORES

2008 «Centros volcánicos oligo-miocénicos (Grupo Calipuy) en la zona Sur de Cajamarca». XIII Congreso Latinoamericano de Geología y XIV Congreso Peruano de Geología, Lima, Resúmenes extendidos, 6 p.

NOBLE, D. y LOAYZA, C.

2004 Field trip: Volcanic rocks and Paleogene geological history in the vicinity of Chilete. Guía de campo, Sociedad Geológica del Perú, XII Congreso Peruano de Geologia, Lima, 12 p.

ONUKI, Y., Y. KATO y K. INOKUCHI

1995 «La primera parte: Las excavaciones en Kuntur Wasi, la primera etapa, 1988-1990». En: Y. Onuki (ed.) Kuntur Wasi y Cerro Blanco, pp. 1-126. Tokyo: Hokusen-Sha. 
ONUKI, Y. y K. INOKUCHI

2011 Gemelos prístinos: el tesoro del templo de Kuntur Wasi. Lima: Fondo Editorial Congreso del Perú.

RAMÓN Gabriel

2008 «Producción alfarera en Piura (Perú): estilo técnico y diacronía». En: Bulletin de l'Institut Français d'Études Andines 37(2): 477-507.

2011 «The swallow potters: itinerant technical styles in the Andes». En: S. Scarcella (ed.) Methodological and practical approaches in ceramic studies, British Archaeological Reports S2193, Oxford, pp. 160-175.

REYES RIVERA, Luís

1980 Geología de los cuadrángulos de Cajamarca, San Marcos y Cajabamba. Lima: INGEMMET.

RICE, Prudence M.

1987 Pottery Analysis. A Source Book. Chicago: The University of Chicago Press.

RIEDERER, J.

ms. Die mikroskopische Untersuchung der Keramik von Montegrande. Berlín: Rathgen-Forschungslabor.

RHODES, Daniel

1973 Clay and glazes for the potter. Philadelphia: Chilton Book Co.

SEKI, Y., SHIMIZU, M., SHIMIZU, M., y S. YOMODA

2009 Informe del análisis científico de los materiales recuperados durante la exploración arqueológica en el valle de Cajamarca, en el año 2001. Nacional Museum of Ethnology, Osaka y Universidad de Toyama, Japón.

SHIMADA, I., ELERA, C. G., CHANG, V., NEFF, H., GLASCOCK, M., WAGNER, U. y R. GEBHARD

1994 «Hornos y producción de cerámica durante el periodo Formativo en Batan Grande, Costa Norte del Perú». En: I. Shimada (ed.) Tecnología y organización de la producción de cerámica prehispánica en los Andes: 67-119. Lima: PUCP.

STOLTMAN, James

1991 «Ceramic petrography as a technique for documenting cultural interaction: an example from the upper Mississippi valley». En: American Antiquity 56(1): 103-120.

TELLENBACH, Michael

1986 Die Ausgrabungen in der formativzeitlichen Siedlund, Montegrande, Jequetepeque-Tal, Nord-Peru. AVAMaterial 39, München.

TERADA, Kazuo y Yoshio ONUKI

1988 Las excavaciones en Cerro Blanco y Huacaloma, Cajamarca, Perú 1985. Tokyo: University of Tokyo Press.

ULBERT, Cornelius

1994 Die Keramik der formativzeitlichen Siedlung Montegrande, Jequetepequetal, Nord-Peru. KAVA Band 52. Philipp von Zabern. Mainz am Rhein.

VELDE, Bruce y Isabelle DRUC

1999 Archaeological Ceramic Materials. Berlin: Springer Verlag.

WAGNER, U., BRANDIS, S. v., ULBERT, C., WAGNER, F.E., MÜLLER-KARPE, H., RIEDERER, J. y M. TELLENBACH

1988 «First results of a Mössbauer and neutron activation analysis study of recent ceramic finds from Montegrande, Peru». En: R. M. Farquhar, R. G. V. Hancock y L. A. Pavlish, (eds.) Proceedings of the 26th International Archaeometry Symposium: 35-42. Toronto: University of Toronto.

WAGNER, U., GEBHARD, R., MURAD, E., RIEDERER, J., SHIMADA, I., ULBERT, C., WAGNER, F. E., y A. M. WIPPERN

1994 «Condiciones de cocción y características de composición de la cerámica formativa: Perspectiva arqueométrica». En: I. Shimada (ed.) Tecnología y organización de la producción de cerámica prehispánica en los Andes: 121-156. Lima: PUCP.

YOMODA, Shinsuke

2002 Application of mineral sciences to the archaeological samples of pre-Andes civilization. Tesis de maestría. Graduate School of Science and Engineering, University of Toyama. (En japones). 